\title{
Representação Social das Relações Sexuais: um Estudo Transgeracional entre Mulheres
}

\author{
Kay Francis Leal Vieira \\ Centro Universitário de João Pessoa, PB, Brasil. \\ Maria Valdênia Soares Arruda \\ Centro Universitário de João Pessoa, PB, Brasil.
}

\author{
Renata Pires Mendes da Nóbrega \\ Centro Universitário de João Pessoa, PB, Brasil. \\ Priscila Monique de Melo Veiga \\ Centro Universitário de João Pessoa, PB, Brasil.
}

\begin{abstract}
Resumo: Relações sexuais são influenciadas por normas, valores cristãos, cultura, política e economia, fazendo com que a mulher, ao longo da história, só as praticasse após o casamento. Entretanto, muitas mudanças ocorreram, sendo perceptíveis, atualmente, transformações conceituais e práticas no comportamento sexual das mulheres. Frente ao exposto, objetivou-se analisar as representações sociais das mulheres acerca das relações sexuais. Tratou-se de uma pesquisa descritiva, com abordagem qualitativa, cuja amostra foi composta por 60 mulheres, divididas em quatro gerações, sendo 15 adolescentes, 15 adultas jovens, 15 mulheres na meia-idade e 15 idosas, que responderam a um questionário. Os dados foram analisados por meio técnica de Análise de Conteúdo Temática proposta por Bardin. Observou-se que as relações sexuais foram representadas consensualmente entre as gerações através da afetividade e do prazer. As mulheres representaram as relações sexuais por meio dos aspectos biopsicossociais que compõem a sexualidade humana, apresentando semelhanças e divergências entre as gerações.

Palavras-chave: Representação social, Sexualidade, Relação sexual, Mulheres.
\end{abstract}

\section{Social Representation of sexual relations: a transgenerational study among women}

\begin{abstract}
Sexual relations are influenced by norms, Christian values, culture, politics, and economy, and that is why women, throughout history, only practiced sex after marriage. However, many changes have occurred, and now there are conceptual and practical transformations in the sexual behavior of women. This text presents a qualitative research aiming at analyzing women's social representations of sexual relations. The sample was composed by 60 women. The 60 women in the sample divided into 4 generations: 15 teenagers, 15 young adults, 15 middle-age women, and 15 old women. The qualitative information was analyzed by Bardin's Thematic Content Analysis. It was found that sexual relations were represented, consensually between generations, by affection and pleasure. Women represented sexual relations through the biopsychosocial aspects that compose sexuality, presenting similarities and differences among generations.
\end{abstract}

Keywords: Social representation, Sexuality, Sexual Relation, Women. 


\title{
Representación Social de las relaciones sexuales: un estudio transgeneracional entre las mujeres
}

\begin{abstract}
Resumen: Las relaciones sexuales reciben influencia de las normas, de los valores cristianos, de la cultura, de la política y de la economía, de manera que las mujeres a lo largo de la historia solían llevarlas a cabo solamente tras el matrimonio. Sin embargo, sucedieron muchos cambios, viéndose hoy en día claramente transformaciones conceptuales y prácticas en el comportamiento sexual de las mujeres. De ese modo, este texto trata de una investigación con enfoque cualitativo que tuvo el objetivo de analizar las representaciones sociales de las mujeres sobre las relaciones sexuales. La muestra estuvo compuesta por 60 mujeres divididas por cuatro generaciones: 15 adolescentes, 15 adultas jóvenes, 15 mujeres de mediana edad y 15 adultas mayores, que contestaron un cuestionario. Los datos fueron analizados mediante la técnica de análisis de contenido temático propuesta por Bardin. Se observó que las relaciones sexuales fueron representadas por consenso entre generaciones a través de afecto y placer. Las mujeres representaron las relaciones sexuales a través de los aspectos biopsicosociales que constituyen la sexualidad humana, presentando similitudes y diferencias entre generaciones.

Palabras clave: Representación Social, Sexualidad, Relación Sexual, Mujeres.
\end{abstract}

\section{Introdução}

A sexualidade é compreendida como um elemento que dá sentido e significado à existência humana, representando uma função vital do indivíduo, da qual fazem parte múltiplos fatores biológicos, psicológicos, sociais e culturais, transmitidos de geração em geração.

Comumente, os termos sexualidade, sexo e relações sexuais são utilizados como sinônimos, distorcendo-se seus significados reais. Diante dessa problemática, a Organização Mundial de Saúde (OMS) publicou algumas definições operacionais em relação à sexualidade. Nesse documento, ressalta-se que, embora o termo "sexo" seja utilizado em diversos idiomas como significado de "atividade sexual", a OMS (Krug, Dahlberg, Mercy, Zwi, \& Lozano, 2002) destaca que ele se refere às características biológicas que definem humanos como mulheres e homens. Já a sexualidade é entendida como "um aspecto central do ser humano do começo ao fim da vida e circunda sexo, identidade de gênero e papel, orientação sexual, erotismo, prazer, intimidade e reprodução" (p. 27).

A relação sexual é uma atividade que envolve ao menos duas pessoas, compreendendo, no mínimo, uma prática sexual. Atribui-se a uma ampla diversidade de comportamentos entre indivíduos, voltados para procriação e para a obtenção do prazer erótico de pelo menos um dos membros envolvidos, inde- pendentemente de haver penetração, orgasmo e fins reprodutivos (Giami, 2008).

Apesar das relações sexuais, durante muito tempo, terem sido compreendidas como algo exclusivamente ligado à reprodução, sabe-se que, atualmente, deixou de ser uma mera necessidade biológica de perpetuação da espécie, para se tornar, também, uma necessidade psicológica, profundamente influenciada pelos padrões sociais e culturais (Silva, 2006). Obedece a uma necessidade fisiológica e emocional do indivíduo e se manifesta de forma diferenciada nas diferentes fases do desenvolvimento humano.

\section{Aspectos sócio-históricos da sexualidade}

Fenômeno complexo, asexualidadeéconstituídapor múltiplos aspectos, que variam de acordo com o contexto social, cultural e religioso, alterando a concepção, aceitação e vivências da sexualidade das mulheres ao longo da história. Dessa forma, é extremamente necessária a compreensão de seu desenvolvimento sócio-histórico.

No princípio da civilização, segundo as teorias de Engels (1982), as atividades sexuais, entre homens e mulheres, eram livres, mas isso não percutia como promiscuidade. Dentro das sociedades chamadas de clãs, os relacionamentos ficaram ao longo do tempo exercendo uma determinada ordem, acabando com o relacionamento livre; tornou-se conhecida a figura 
do patriarca da família. Nessa época, a relação sexual toma uma conotação diferente e passa a ser vista como meio de procriação e formação familiar. Mesmo assim, os homens poderiam ter relacionamento extraconjugal; já as mulheres eram para o casamento e para as tarefas domésticas e se casavam após a primeira menstruação.

Para Costa (1986), a sexualidade era vista de maneira promíscua pela concepção religiosa e era carregada de tabus. No século XVI, surgem a modernização da sociedade e a ascensão da burguesia, aliadas às influências da Igreja e dos moralistas no controle da vida social. A sexualidade foi fortemente influenciada pelas ideias cristãs, culturais e econômicas. A mulher só poderia perder a virgindade depois do casamento $\mathrm{e}$ as relações sexuais eram para procriação. Na Europa, somente a partir do século XVIII o sexo uniu-se ao amor e começou a fazer parte do casamento, dada a possibilidade do parceiro (Giddens, 1993).

A partir da Revolução Sexual da década de 1960, com o surgimento da pílula anticoncepcional, ocorreu uma mudança da vida sexual das pessoas, tendo em vista que passaram a praticar o sexo pelo prazer e não apenas pela reprodução. Devido à realização da prática sexual de forma mais livre, algumas consequências negativas foram desencadeadas, a exemplo de uma maior transmissão da AIDS. A partir daí surge o paradoxo da convivência entre comportamentos sexuais mais livres e um moralismo social arraigado.

\section{Sexualidade e desenvolvimento}

Além da influência sociocultural, a sexualidade humana apresenta características específicas, de acordo com a fase do desenvolvimento em que se encontra cada indivíduo. De acordo com a classificação da OPAS/OMS (OPAS, 1998), as fases do desenvolvimento dispõem-se em oito categorias: recémnascido ( 0 a 1 mês de vida), infância ( 1 mês a 23 meses de idade), criança pré-escolar ( 2 a 5 anos), criança com idade escolar (6 a 9 anos), adolescente (10 a 19 anos), adulto ( 20 a 44 anos), meia-idade ( 45 a 59 anos) e idoso (60 anos a mais). Quanto às adolescentes, usaremos as definições do ECA (Estatuto da Criança e do Adolescente, Lei 8.069/1990), o qual diz que adolescente é aquele que está entre 12 e 18 anos.

Berger (2003) ressalta que é de grande importância levar em consideração o desenvolvimento biossocial, cognitivo e psicossocial em cada uma dessas gerações, visto que estas nem sempre se desenvolvem, por completo, de acordo com suas respectivas fases. A adolescência, especificamente, é marcada por mudanças, crises, dúvidas e descobertas. Nesse direcionamento, Alencar (2010) ressalta que é uma fase na qual ocorrem os primeiros envolvimentos, chamados de "ficar", caracterizando-se, ainda, pelas descobertas e experiências sexuais, o surgimento da masturbação e o conflito de deixar de ser virgem ou não.

Para as mulheres adultas, os dilemas sexuais estão interligados às questões sócio-históricas, nas quais se percebe que foi imposto ao homem o papel ativo na relação sexual e social. Com esse domínio econômico, se explicaria a dependência financeira da mulher e sua aceitação dos "deveres conjugais", em que constava o "serviço sexual" (Berger, \& Giffin, 2005). Todavia, esse conceito vem mudando e, atualmente, a mulher vem conquistando seu espaço na sociedade, no trabalho, sendo mais ativa na relação sexual, em que não veem mais o sexo como apenas obrigação ou procriação.

De acordo com Alencar (2010, p. 25), "com o surgimento do anticoncepcional e da camisinha, a mulher tem conseguido mais respeito na área do comportamento sexual, praticando o sexo sem se expor às DSTs/AIDS, nem à gravidez indesejada", representando um aspecto importante, pois vivenciam sua sexualidade de forma mais ampla e saudável. As mulheres adultas discorrem sobre as DSTs e gravidez indesejada com mais liberdade, como também se previnem mais em relação às adolescentes (Berger, 2003). No cotidiano, com as responsabilidades diante do trabalho, da criação dos filhos e da relação com seu cônjuge, as mulheres acabam desenvolvendo estresse, que pode prejudicar sua libido. Portanto, devido aos tantos papéis que a mulher assume durante seu dia a dia, algumas vezes ficam cansadas, e com pouca disposição para a atividade sexual.

De acordo com Alencar (2010), a mulher ao atingir a menopausa pode sentir o desejo sexual com mais vigor, por não ter a preocupação de engravidar, passando a usufruir de uma sexualidade mais completa. É errôneo afirmar que as pessoas perdem suas habilidades sexuais quando estão envelhecendo. O que acontece é que a atividade sexual, assim como várias outras, pode tornar-se menos valorizada com a idade. Consequentemente, haverá uma diminuição da frequência das práticas sexuais, não significando, porém, o término do desejo sexual (Gradim, Sousa, \& Lobo, 2007). Com o envelhecimento, a mulher idosa não precisa se privar do trabalho, relações sexuais, vida social e lazer. Há um preconceito cultural quanto às práticas sexuais na velhice, mas, independentemente 
disso, existe a necessidade da relação sexual continuada em qualquer idade para o ser humano, não existindo idade em que esta seja favorável. A sociedade, a cultura e a falta de conhecimento contribuem para a problemática da aceitação das relações sexuais entre pessoas idosas (Ballone, \& Moura, 2002).

Manifestações sexuais não desaparecem com a idade, apesar do preconceito ainda existente sobre esse fato. Quando os idosos têm uma qualidade de vida satisfatória, incluindo um equilíbrio emocional, a sexualidade também tende a se manter com melhor qualidade, visto que, quando há uma diminuição da frequência das relações sexuais no idoso, uma das causas pode ser o surgimento de doenças que se originam com o desgaste físico, psíquico e social, com o passar dos anos. Mas é importante salientar que as relações sexuais não são uma "dádiva apenas dos mais jovens, é, sobretudo, um presente da natureza e necessidade orgânica de todos, independentemente da idade, credo, raça ou posição socioeconômica" (Meira, 2002, p. 82).

\section{A Teoria das Representações Sociais}

Devido a sua complexidade, a sexualidade necessita ser compreendida com um enfoque diferenciado, que não a limite apenas aos seus aspectos fisiológicos. Por se tratar de construto socialmente elaborado, merece uma análise advinda da Psicologia Social, sob a égide psicossociológica da Teoria das Representações Sociais (Moscovici, 1978).

O termo representação social surgiu com Serge Moscovici, no campo da Psicologia Social, porém a origem desse conceito provém de estudos realizados por Durkheim, no campo da Sociologia, sob a denominação de representação coletiva. As representações sociais referem-se a uma forma de conhecimento, socialmente elaborada e partilhada, com um objetivo prático, e que contribui para a construção de uma realidade comum a um conjunto social (Jodelet, 2001).

Moscovici $(1978 ; 2010)$ compreende as representações sociais como um sistema de valores, ideias e práticas que apresentam dupla função: estabelecer uma ordem que possibilita às pessoas orientarem-se em seu mundo material e social e controlá-lo; e também possibilitar que a comunicação seja possível entre os membros de uma comunidade, fornecendo-lhes um código para nomear e classificar, sem ambiguidade, os vários aspectos de seu mundo e da sua história individual e social.
Trata-se de um saber prático, produzido nas interações e na comunicação entre os grupos sociais, os quais refletem a situação dos indivíduos no que se refere aos assuntos cotidianos (Ferreto, 2010). São consideradas necessárias, pois guiam o indivíduo no modo de nomear e definir conjuntamente os diferentes aspectos da realidade diária, no modo de interpretar esses aspectos, tomar decisões e, eventualmente, posicionar-se frente a eles de forma defensiva (Jodelet, 2001).

A elaboração e o funcionamento de uma representação podem ser compreendidos através dos processos de objetivação e ancoragem, que representam a imbricação e a articulação entre a atividade cognitiva e as condições sociais em que são forjadas as representações. Moscovici (1978) sistematiza esses dois processos postulando que são como faces da mesma moeda.

A objetivação é o processo pelo qual o indivíduo reabsorve um excesso de significações, materializando-as, ou seja, é um processo de construção formal de um conhecimento pelo indivíduo (Jodelet, 2001). Segundo Moscovici (2010), a objetivação une a ideia de não familiaridade à de realidade e torna verdadeira a essência da realidade. Objetivar é descobrir a qualidade icônica de uma ideia ou ser impreciso; é reproduzir um conceito em uma imagem. A transformação do que não é familiar em algo familiar não se processa de maneira automática na vida dos indivíduos, mas conta com a participação da memória e das conclusões pré-estabelecidas (Saraiva, 2010).

Através da objetivação, o indivíduo torna concreto aquilo que é abstrato. Ela transforma um conceito em imagem de uma coisa e o retira de seu quadro conceitual científico. Trata-se de privilegiar certas informações em detrimento de outras, simplificando-as, dissociando-as de seu contexto original de produção e associando-as ao contexto do conhecimento imagético do sujeito ou do grupo (Trindade, Santos, \& Almeida, 2011).

O outro processo formador das representações sociais, a ancoragem, como instrumento do saber, é uma modalidade que permite compreender como os elementos de representação não só exprimem relações sociais, mas também contribuem para construí-las (Jodelet, 2001). A ancoragem, portanto, assegura o elo entre a função cognitiva de base da representação e a sua função social e objetiva os elementos imaginativos para servir na elaboração de novas representações. 
Sobre a ancoragem, Moscovici (1978) afirma que é um processo que transforma algo estranho, perturbador, intrigante, em nosso sistema particular de categorias e o compara com um paradigma de uma categoria que pensamos ser apropriada. $\mathrm{O}$ processo de ancoragem transfere, portanto, aquilo que nos é desconhecido para o esquema de referência e realiza uma comparação e interpretação por meio de algo já conhecido. Esse processo diz respeito à maneira pela qual o pensamento enraíza-se no social e volta a ele, pois, ao se converter em categoria e integrar-se à grade de leitura do mundo do sujeito, instrumentaliza-se um novo saber, e o sujeito recorre ao que é familiar para fazer uma espécie de conversão da novidade. Dessa forma, a ancoragem é o elo que liga os sistemas de conceitos já existentes na sociedade aos nossos sistemas de pensamento, construindo novas interpretações da realidade do senso comum (Arruda, 2002).

Percebe-se, então, que a ancoragem é um processo interligado à objetivação, em que esse último contribui para o surgimento de uma representação social frente a um novo objeto, por meio da materialização de uma entidade abstrata, que foi ancorada pela classificação e pela nomeação (Saraiva, 2010). Segundo Coutinho (2005), a ancoragem dirige a memória para dentro, buscando coisas, eventos e pessoas que ela identifica como um protótipo, ou se reconhece nomeando-o.

Frente ao exposto, o presente estudo objetivou analisar as representações sociais da sexualidade elaboradas por mulheres de diferentes gerações: adolescentes, adultas jovens, adultas de meia-idade e idosas no município de João Pessoa - PB.

\section{Método}

Tratou-se de um estudo de campo, do tipo descritivo, de natureza qualitativa, com delineamento de levantamento, fundamentada nos aportes teóricos e metodológicos da Teoria das Representações Sociais (Moscovici, 2003).A pesquisa foi realizada em uma Escola Estadual de Ensino Fundamental e em uma universidade particular, ambas situadas em João Pessoa - PB. Todas as adolescentes eram estudantes da referida escola, já as mulheres adultas eram acadêmicas e funcionárias da universidade.

A amostra foi do tipo não probabilística por quota, da qual fizeram parte 60 mulheres divididas em quatro grupos, de acordo com os seguintes critérios: 15 mulheres adolescentes, entre 12 e 17 anos, definidas segundo o ECA; 15 mulheres adultas entre 20 e 44 anos; 15 mulheres na meia-idade, entre 45 e 59 anos e 15 idosas acima de 60 anos, critérios definidos pela OPAS (1998).

$\mathrm{O}$ instrumento utilizado foi um questionário composto de duas partes, sendo a primeira destinada às variáveis sociodemográficas, almejando-se o perfil da amostra. A segunda parte contava com uma questão aberta e três de múltipla escolha, baseadas nos objetivos do estudo. Os dados foram analisados por meio da técnica de Análise de Conteúdo Temático proposta por Bardin (2010), com o objetivo de inferir conhecimentos a partir das respostas das mulheres entrevistadas.

Este estudo foi aprovado pelo Comitê de Ética em Pesquisa do Centro Universitário de João Pessoa - UNIPE e seguiu todos os preceitos éticos da Resolução no 466/12 do Conselho Nacional de Saúde, referente às pesquisas envolvendo seres humanos.

\section{Resultados e discussões}

\section{Perfil da Amostra}

A amostra total foi composta por 60 mulheres divididas em quatro grupos, de acordo com a idade das participantes. O primeiro grupo foi formado por 15 adolescentes, estudantes do Ensino Médio, com idades entre 15 a 17 anos ( $\mathrm{M}=16,6$ anos), em sua maioria solteiras $(53,3 \%)$, adeptas das religiões católica $(46,7 \%)$ e evangélica ( $46,7 \%)$, e com renda familiar de até 3 salários mínimos (60\%).

O segundo grupo foi composto por 15 mulheres adultas jovens com idades entre 19 e 44 anos ( $\mathrm{M}=30,5$ anos). Constatou-se que a maioria era casada $(53,33 \%)$, adepta da religião católica $(60 \%)$ e possuía renda familiar de até 3 salários $(53,33 \%$,). No que tange à escolaridade, observou-se uma predominância no superior incompleto (53,33\%).

O terceiro grupo foi composto por 15 mulheres adultas de meia-idade, que variaram de 45 a 59 anos $(M=53,53)$, sendo a maioria adepta do catolicismo (66,66\%). Em relação à situação conjugal, averiguou-se que $40 \%$ eram casadas e $33,33 \%$ divorciadas. A maioria informou ter concluído o Ensino Superior (40\%) e possuir renda familiar de até 3 salários mínimos $(43,66 \%)$ e 3 a 5 salários mínimos (33,33\%).

Por fim, o quarto grupo foi composto por 15 mulheres idosas com idades entre 60 a 79 anos 
( $M=66,66)$, sendo a maioria $(53,33 \%)$ de religião católica. Em relação à situação conjugal, verificou-se que $33,33 \%$ eram viúvas, $26,66 \%$ eram casadas, e, o restante, solteiras (20\%) e divorciadas (20\%); a renda familiar foi de até 3 salários mínimos (80\%) e o grau de escolaridade está em Fundamental incompleto (26,66\%), Fundamental completo (20\%), Médio incompleto $(6,66 \%)$, Médio completo (26,66\%) e Pós-graduação (20\%).

\section{Práticas Sexuais}

Outros quatro itens compuseram o questionário: o primeiro investigava se as mulheres eram ativas sexualmente e o segundo item versava acerca da frequência das mulheres com vida sexual ativa (Tabela 1).

Conforme pode ser observado na Tabela 1, a maioria das adolescentes afirmou ter vida sexual ativa, corroborando dados apresentados na literatura que caracterizam o início da vida sexual entre os 15 e 19 anos (Paiva, Calazans, Venturi, \& Dias, 2008). De acordo com a Pesquisa Nacional de Saúde do Escolar - 2012 (IBGE, 2013), a adolescência é vivenciada de formas distintas, em cada sociedade e em um corte histórico, em cada grupo social e cultural. O adolescente na busca por sua identidade faz experimentações de situações nunca antes vividas, como o primeiro beijo, o primeiro toque, o primeiro namoro, e atribui aos grupos de convívio valores afetivos importantes. Essas experimentações podem ser atribuídas a uma elevada pontuação de adolescentes que são ativas sexualmente, reconhecendo-se que a própria sociedade atual tem fortalecido uma iniciação sexual na adolescência, diante da mídia, dos grupos de iguais marcados pela simbologia do consumo e a valorização do corpo.

O terceiro item do questionário investigou o grau de satisfação das mulheres ativas e, por fim, foi questionado se elas apresentavam alguma dificuldade de ordem física, psicológica, conforme pode ser demonstrado na Tabela 2.

Tabela 1

Distribuição percentual das práticas sexuais das mulheres participantes.

\begin{tabular}{lcccc}
\hline Frequência & Adolescentes & Mulheres jovens & Mulheres meia-idade & Mulheres idosas \\
\hline Sim & $60 \%$ & $80 \%$ & $53 \%$ & $13 \%$ \\
Não & $33 \%$ & $20 \%$ & $47 \%$ & $87 \%$ \\
Nunca praticaram & $7 \%$ & - & - & - \\
1 a 3 vezes/semana & $22 \%$ & $100 \%$ & $62 \%$ & $7 \%$ \\
4 a 5 vezes/semana & $22 \%$ & - & - & - \\
1 vez/mês & - & - & - & $7 \%$ \\
No momento não & - & - & - & $73 \%$ \\
praticam & - & - & $38 \%$ & - \\
Não praticam & $56 \%$ & - & & \\
Outra & & &
\end{tabular}

Tabela 2

Distribuição percentual da relação práticas sexuais X satisfação e dificuldades.

\begin{tabular}{lccccc}
\hline Critério & Frequência & Adolescentes & Mulheres jovens & Mulheres meia-idade & Mulheres idosas \\
\hline \multirow{4}{*}{ Grau de } & Satisfeita & $56 \%$ & $67 \%$ & $37 \%$ & $25 \%$ \\
Satisfação & Muito satisfeita & $44 \%$ & $33 \%$ & $13 \%$ & $25 \%$ \\
& Não satisfeita & - & - & $50 \%$ & $25 \%$ \\
& Às vezes & - & - & - & $25 \%$ \\
& Física & $27 \%$ & $7 \%$ & $38 \%$ & $22 \%$ \\
Dificuldades & Psicológica & $20 \%$ & $13 \%$ & $50 \%$ & $14 \%$ \\
& Não apresentou & $53 \%$ & $80 \%$ & $12 \%$ & $57 \%$ \\
& Ambas & - & - & - & $7 \%$ \\
\hline
\end{tabular}


Observou-se, de modo geral, que as mulheres adultas jovens, que estão ativas, vivenciam de forma satisfatória sua vida sexual, o que corrobora o fato das mulheres estarem evidenciando seus desejos, assumindo um papel mais ativo na relação. Conforme Alencar (2010), muitas mulheres atualmente não encaram mais o sexo como sendo uma obrigação, ou só pela procriação. Elas expressam ter excitação e desejo sexual de maneira similar aos homens, tendo mais liberdade para inferir sobre a prática sexual enfatizando o que gostam e como gostam. As dificuldades foram significativamente pequenas, em termos de quantidade, no entanto não deixa de ser preocupante a existência das mesmas, pois dependendo da gravidade pode vir a interferir nas vivências sexuais dessas mulheres.

Verificou-se nas mulheres de meia-idade um dado preocupante e que merece atenção que são as dificuldades apresentadas por elas, principalmente considerando que as mesmas influenciam na relação dessas mulheres. Portanto, surge também a necessidade de se investigar se essas dificuldades estão de alguma forma relacionada com a insatisfação da relação sexual, representada por $50 \%$ das mulheres, uma vez que a mulher na meia-idade está vivenciando o período de climatério, que é a transição do período reprodutivo para um não reprodutivo.

Conforme Valença, Nascimento Filho e Germano (2010), o climatério pode ser interpretado como um processo de transformação física, emocional e fisiológica, não patológico e, principalmente, da individualidade da mulher. Essas mudanças interferem diretamente na sexualidade dela nesse período, o que pode estar ligado às dificuldades físicas e psicológicas apresentadas, visto que as mudanças são em nível biopsicossocial-espiritual. Entre as mudanças, algumas são devidas à brusca queda ou desequilíbrio hormonal (dimensão biológica) e outras se relacionam ao estado geral da mulher e ao estilo de vida adotado até então. A autoimagem (dimensão psicológica), o papel e as relações sociais (dimensão social), as expectativas e projetos de vida (dimensão espiritual) (Valença et al., 2010).

Por fim, a maioria das mulheres idosas afirmou não apresentar dificuldade (57\%), o que pode ser resultado de não estarem ativas sexualmente (87\%). De acordo com Dantas Neto, Santana, Lucena, Soares e Lima (2014), para algumas pessoas, com a progressão da idade, há uma concomitante anulação do desejo sexual, enquanto, para outras, há apenas uma modificação. Entretanto, de modo geral, o que se evidencia é que para uns e outros é uma constante e cômoda negação do desejo do idoso pela sociedade. E embora a sociedade busque quebrar o estereótipo do idoso assexuado muitas vezes ele ainda é encontrado entre os próprios idosos.

\section{Análise de Conteúdo}

Com base no discurso das participantes, observou-se a emersão de uma única categoria empírica com variações apenas no que concerne às subcategorias, sendo quatro para as adolescentes, cinco para as mulheres adultas jovens, quatro para as mulheres adultas de meia-idade e três para as mulheres idosas (Tabela 3).

É interessante observar que, mesmo sendo grupos diferenciados, infere-se que as mulheres ancoram suas representações sociais nos aspectos sócio-históricos e culturais construídos nos processos de interação e comunicação social acerca da sexualidade feminina. Neste sentido, foram constatadas semelhanças e divergências no que se refere ao significado das relações sexuais para as gerações pesquisadas.

Tabela 3

Categorias e subcategorias de análise de conteúdo temático.

\begin{tabular}{lcccc}
\hline \multirow{2}{*}{ Categoria } & Adolescentes & Adultas jovens & Adultas meia-idade & Idosas \\
\cline { 2 - 5 } & Subcategorias & Subcategorias & Subcategorias & Subcategorias \\
\hline \multirow{2}{*}{$\begin{array}{l}\text { 1. prazer } \\
\text { das relações } \\
\text { sexuais }\end{array}$} & 2. afetividade & 1. prazer & 1. prazer & 1. prazer \\
& 3. confiniança & 3. intimidade & 2. afetividade & 2. afetividade \\
& & 4. casamento & 4. tipos de relações sexuais & 3. complemento \\
\end{tabular}


A primeira forma de objetivação foi o Prazer, categoria essa que emergiu para todos os grupos pesquisados. Percebe-se, portanto, que para as mulheres, independentemente da faixa etária, a relação sexual representa um ato de obtenção do prazer, conforme pode ser verificado nos discursos:

[...] é um meio de sentir prazer entre dois corpos... é uma relação entre dois corpos que um dá prazer ao outro... um ato de prazer sexual... é a relação entre duas pessoas a fim de atingir o prazer sexual... visando o bem-estar e prazer... troca de prazer... que satisfaçam aos dois... é uma química prazerosa... experiência humana. marcada pelo prazer... ato de prazer... um ato prazeroso.

Percebe-se que a existência do prazer é um fator importante, devendo estar presente nas práticas sexuais das pessoas envolvidas durante a relação, não sendo algo apenas destinado aos homens. Tal fato pode ser consequência da Revolução Sexual da década de 1960, pois este foi o momento do surgimento da pílula anticoncepcional, a qual acabou proporcionando uma reviravolta na vida dos indivíduos, em especial das mulheres, tendo em vista que ao longo do tempo elas passaram a praticar as relações sexuais mais livremente com o intuito de obter o prazer.

A Afetividade também foi outra objetivação na qual houve consenso entre as mulheres. As participantes ressaltaram a expressão dos sentimentos como item fundamental para as atividades sexuais, conforme pode ser observado nas seguintes falas:

[...] uma forma de expressar um sentimento por alguém... é você ter um sentimento por uma pessoa... algo que envolve amor, carinho, compreensão, respeito... uma troca de afeto, carinho, respeito... ato de amor... união entre casais que se amam... fazer quando se gosta... cumplicidade, interação entre duas pessoas... com muito amor... é muito bom e com amor.

Verifica-se, então, que o exercício da sexualidade vai muito além do ato sexual em si. Embora exista a importância do prazer nas relações sexuais, a afetividade tem papel essencial na relação. Corroborando tais achados, o estudo realizado por Melo e Santana (2005) revelou que os participantes ressal- taram a presença de carícias, do toque, da afetividade como sendo fundamental durante a relação sexual. As autoras complementam que para haver a completude da relação sexual é necessária a presença da afetividade. Em outra pesquisa, foi constatado que as mulheres representavam as práticas sexuais como uma ação pautada na cumplicidade, no carinho e no sentimento (Costa, \& Fernandes, 2012).

Quanto à subcategoria Intimidade houve consenso apenas entre as adolescentes e adultas jovens, que declararam que as relações sexuais consistiam em um relacionamento íntimo entre duas pessoas, como pode ser ressaltado nas seguintes falas: "[...] uma intimidade avançada com uma pessoa especial... é a intimidade de um casal... uma relação íntima entre duas pessoas... momento íntimo entre duas pessoas que se amam... é um momento íntimo, entre parceiros”. De acordo com Melo e Santana (2005), o ato sexual também pode ser representado como o contato mais íntimo entre pessoas, uma forma de comunicação e conhecimento, que ultrapassa a experiência física.

As adultas jovens e as de meia-idade representaram a relação sexual através da objetivação Casamento, na qual as atividades sexuais foram vistas como algo fundamental e necessário para o relacionamento. Isto pode ser constatado através das seguintes falas: “[...] é a necessidade do casamento... é fundamental num relacionamento conjugal... um complemento de uma relação entre casais... é um relacionamento de múltipla participação... só faço por causa do marido".

Percebe-se, através dos discursos, que embora as atividades sexuais sejam vistas como um complemento para o relacionamento, ainda existem mulheres que veem essa prática como necessidade do casamento, papel da esposa e que muitas vezes só a realizam pelo marido. Sendo assim, observa-se que essas mulheres ancoram suas representações no momento histórico e cultural no qual predominava o modelo patriarcal, devendo ser obedientes, respeitando e servindo aos desejos do marido. Neste sentido, fica claro observar a maneira como a representação social compartilhada sobre a vida sexual feminina orienta a conduta e os comportamentos das mulheres da presente pesquisa.

Em um estudo realizado por Araújo, Queiroz, Moura e Penna (2013), do qual participaram 40 mulheres com idade variando de 35 a 65 anos, foi constatado que 23 delas objetivaram as relações sexuais como sendo "sexo sem vida/ruim". Por sua vez, 14 dessas participantes, afirmaram manter vida 
sexual ativa por ser função e responsabilidade da mulher satisfazer o prazer sexual do marido. Nesse sentido, observa-se que, mesmo diante da Revolução Sexual, da inserção da mulher no mercado de trabalho e em outros âmbitos, tais representações ainda se fazem presentes na vida dessas mulheres, limitando a conduta sexual das mesmas diante das suas relações interpessoais.

$\mathrm{Na}$ análise das representações sociais das relações sexuais para as gerações pesquisadas observou-se o surgimento de objetivações específicas para cada grupo etário. Como a Confiança, que foi evidenciada apenas no grupo das adolescentes, onde foi possível perceber que as mesmas representaram a relação sexual como um ato de confiança em que há uma entrega ao outro, mediante interpretação dos seguintes discursos: "[...] é uma forma de mostrar a confiança que você tem no parceiro e em si mesmo... é você se entregar ao outro".

Corroborando a fala das adolescentes, no estudo de Costa e Fernandes (2012), os adolescentes elucidaram como fator importante a confiança, além de elencarem outros pontos como: respeito, compreensão e cuidado mútuo. Segundo Cardoso (2008), as pessoas têm uma necessidade de confiar em outras, em um processo que traz satisfação emocional para o indivíduo nas suas relações interpessoais. E quanto à relação sexual, não é diferente, pois quando a confiança é estabelecida, representa uma segurança psicológica para vivenciar as práticas sexuais.

A subcategoria Relação Homo/Hétero foi identificada apenas no grupo das adultas jovens, no qual a relação sexual foi vista como uma prática de pessoas do mesmo sexo ou não, como ilustram as seguintes falas: "uma relação entre duas pessoas de sexos opostos... momento íntimo, entre parceiros, sexos opostos ou não". Interessante observar, através dos discursos, que a fala dessas jovens se ancoram em duas vertentes: a primeira - na representação social cuja prática sexual é destinada a pessoas que possuam sexos opostos; a segunda - no reconhecimento da homossexualidade, em que pessoas do mesmo sexo também têm direito a vivência da prática sexual entre si.

Como aponta Foucault (1998), é no interior de um determinado momento histórico, a partir de contextos específicos, que começam a surgir discursos e práticas que visam responder às demandas sociais, políticas ou morais. Nesse momento histórico se percebe cada vez mais a afirmação de relações homossexuais e os novos padrões de família, tornando assim compreensível essa representação social no discurso das mulheres.

A subcategoria Tipos de Relação Sexuais emergiu apenas para o grupo das adultas de meia-idade. Para estas mulheres, a relação sexual está representada pelas práticas envolvendo os órgãos sexuais, conforme demonstrado nas seguintes falas: "todas as formas de atividade sexual, onde há penetração, tanto anal ou vaginal... é a junção de dois órgãos". Nesta representação percebe-se que as mulheres ancoraram suas representações em aspectos relacionados ao ato sexual em si. Apesar dos preceitos, do senso comum, afirmarem que as mulheres, após atingirem a menopausa, não se interessam mais pela prática sexual, por perderem o desejo, a libido, Alencar (2010) afirma que depois da menopausa o desejo sexual pode ser ainda mais forte, pois a mulher não tem mais a preocupação de engravidar e assim passa a usufruir de uma sexualidade mais completa.

Por fim, a relação sexual também foi representada pela objetivação Complemento, que surgiu apenas no grupo das idosas, como pode ser verificado através das falas: "um complemento de duas pessoas... complemento de uma vida a dois... complemento físico e psicológico entre duas pessoas... complementa uma relação afetiva".

É válido ressaltar a representação que as mulheres idosas têm acerca das relações sexuais. Conforme suas objetivações - prazer, afetividade e complemento -, percebe-se a ancoragem nos aspectos gerais da sexualidade. Demonstrando que é imprescindível a atenção, o afeto, a completude, o cuidado um para com o outro. Como retratam Santos, Gonçalves, Azevedo, Pinheiro, Barbosa e Costa (2014), vivenciar a sexualidade não significa ter vida sexualmente ativa, mas ter afeto por parte do parceiro, se sentir amada, cuidada e protegida, expressando a importância que o outro tem em sua vida.

\section{Considerações finais}

É reconhecido que as Representações Sociais têm a função, dentre outras, de compreender a realidade, orientar e conduzir o comportamento das pessoas, sendo tais representações influenciadas por fatores históricos, econômicos, sociais, políticos e ideológicos, assim como dos aspectos simbólicos e culturais com seus valores, crenças, tradições. Neste sentido, pode-se observar, no transcurso da presente 
pesquisa, a influência do desenvolvimento dos conceitos da prática sexual e sexualidade na história e como este influi nas representações das mulheres nas diversas gerações, tomando como referência que em cada momento da história as manifestações sexuais e amorosas, proclamadas como ideais ou não, também são reflexo das transformações. Diante de tantos tabus, especula-se que a força negativa que o grupo de idosas possui, em relação à sua manifestação do desejo ou da atividade sexual, advém das normas de comportamento existentes nos séculos anteriores.

Com a confrontação dos dados e das análises apresentadas, verificou-se que a representação social das relações sexuais se ancoraram nos diversos aspectos que compõe a sexualidade humana e nos valores impostos pela nossa cultura. Mesmo diante de tantos avanços ainda há mulheres que veem a relação sexual como uma prática do casamento. No entanto, constatou-se também que essas representações se objetivaram através da existência de amor, de carinho, de intimidade e, principalmente, do prazer na atividade sexual, o que corrobora a ideia que as mulheres estão tendo um papel mais ativo nessas práticas sexuais, que sentir

\section{Referências}

Alencar, C. M. L. (2010). A mulher e o sexo. São Paulo, SP: Iglu.

Araújo, I. A. A., Queiroz, A. B. A., Moura, M. A. V., \& Penna, L. H. G. (2013). Representações sociais da vida sexual de mulheres no climatério atendidas em serviços públicos de saúde. Texto \& Contexto - Enfermagem, 22(1), 114-122. doi:10.1590/S0104-07072013000100014

Arruda, A. (2002). Teoria das representações sociais e teorias de gênero. Cadernos de Pesquisa, 117(1), 127-147. doi:10.1590/S0100-15742002000300007

Ballone, G. J., \& Moura, E. C. (2002). Sexo e idade. PsiqWeb. Recuperado de http://www.psiqweb.med. $\mathrm{br} /$ site $/$ ?area $=\mathrm{NO} /$ LerNoticia\&idNoticia $=173$

Bardin, L. (2010). Análise de conteúdo. Lisboa: Edições 70.

Berger, K. S. (2003). O desenvolvimento da pessoa: da infância à terceira idade (5a ed.). Rio de Janeiro, RJ: LTC.

Beger, S. M. D., \& Giffin, K. (2005). A violência nas relações de conjugalidade: invisibilidade e banalização daviolênciasexual? CadernosdeSaúdePública,21(2), 417-425. doi:10.1590/S0102-311X2005000200008 o prazer também é importante junto ou não com a existência de sentimentos.

Embora possam existir mulheres que só realizam a atividade sexual para satisfazer o companheiro, não proporcionando prazer a si mesmas, essa realidade está mudando, pois de modo geral, neste estudo, todas as gerações, referiram que o prazer tem que estar presente nahora da prática sexual, equea presença de sentimentos de amor, carinho, companheirismo é fundamental para essas mulheres. Estas têm buscado cada vez mais um amor prazeroso na relação sexual, ou até mesmo só o prazer pelo prazer sem existência de sentimentos, algo que antes era mais vivenciado pelos homens.

No que se refere à aplicabilidade desse estudo, acredita-se que a compreensão da forma como as mulheres percebem, sentem e vivenciam sua sexualidade possibilita uma complementaridade entre o conhecimento científico e o senso comum, trazendo informações relevantes para a saúde sexual e o bem-estar psicossocial das mulheres. Entretanto, são reconhecidas as limitações do presente estudo, diante da complexidade do fenômeno estudado, sendo necessário que novas pesquisas sejam realizadas com este enfoque ainda tão pouco investigado e repleto de tabus e estereótipos.

Cardoso, C. S. C. (2008). Construção da confiança e risco nas relações sexuais e emotivas (Monografia). Universidade Jean Piaget de Cabo Verde, Cabo Verde.

Costa, M. (1986). Sexualidade na adolescência: dilemas e crescimento (8a ed). São Paulo, SP: L \& PM.

Costa, V., \& Fernandes, S. C. S. F. (2012). O que pensam os adolescentes sobre o amor e o sexo? Um estudo na perspectiva das representações sociais. Psicologia \& Sociedade, 24(2), 391-401. doi:10.1590/S0102-71822012000200017

Coutinho, M. P. L. (2005). Depressão infantil e representação social (2a ed.). João Pessoa, PV: Editora Universitária UFPB.

Dantas Neto, F. A., Santana, M. A. S., Lucena, E. C. L., Soares, M. C. S., \& Lima, K. M. M. (2014). Sexualidade na terceira idade: compreensão e percepção do idoso, família e sociedade. Revista da Universidade Vale do Rio Verde, 12(1), 317-326. doi:10.5892/ruvrd.v12i1.1385

Engels, F. (1982). A origem da família, da propriedade privada e do estado (L. Konder, trad., 8a ed.). Rio de Janeiro: Civilização Brasileira. 
Ferreto, L. E. (2010). Representação social no envelhecimento humano. In W. Malagutti, \& A. M. A. Bergo (Eds.), Abordagem interdisciplinar do idoso (pp. 23-36). Rio de Janeiro, RJ: Rubio.

Foucault, M. (1998). História da sexualidade II: o uso dos prazeres. (98a ed.). Rio de Janeiro, RJ: Graal.

Giami, A. (2008). A experiência da sexualidade em jovens adultos na França: entre errância e vida conjugal. Paidéia (Ribeirão Preto), 18(40), 289-304. doi:10.1590/S0103-863X2008000200007

Giddens, A. (1993). A transformação da intimidade: sexualidade, amor e erotismo nas sociedades modernas (Trad. Magda Lopes, 2a ed.). São Paulo: Editora UNESP.

Gradim, C. V. C.; Sousa, A. M. M., \& Lobo, J. M. (2007). A prática sexual e o envelhecimento. Cogitare Enfermagem. 12(2), 204-213. Recuperado de http://ojs.c3sl. ufpr.br/ojs2/index.php/cogitare/article/view/9826

Instituto Brasileiro de Geografia e Estatística - IBGE. (2013). Pesquisa Nacional de Saúde do Escolar - 2012. Rio de Janeiro, RJ: o autor. Recuperado de http://biblioteca.ibge.gov.br/visualizacao/livros/liv64436.pdf

Jodelet, D. (2001). Representações sociais: um domínio em expansão. In: D. Jodelet (Ed.), As representações sociais (pp.17-41). Rio de Janeiro, RJ: Ed. UERJ.

Krug, E. G., Dahlberg, L. L., Mercy, J. A., Zwi, A. B., \& Lozano, R. (Eds.) (2002). Relatório mundial sobre violência e saúde. Genebra: Organização Mundial de Saúde.

Meira, L. B. (2002). Sexos: aquilo que os pais não falaram para os filhos (40a ed.). João Pessoa, PB: Autor Associado.

Melo, A. S. A. F, \& Santana, J. S. S. (2005). Sexualidade: concepções, valores e condutas entre universitários de biologia de UEFS. Revista Baiana de Saúde Pública, 29(2), 149-159. Recuperado de http://inseer.ibict.br/ rbsp/index.php/rbsp/article/view/998

Moscovici, S. (1978). A representação social da psicanálise. Rio de Janeiro, RJ: Zahar.

Moscovici, S. (2003). Representações sociais. Petrópolis, RJ: Vozes.

Moscovici, S. (2010). Representações sociais: investigações em psicologia social (7a ed.) São Paulo, SP:Vozes.

Organização Pan-Americana da Saúde - OPAS. (1998). A saúde no Brasil. Brasília, DF: o autor. Recuperado de http://livros01.livrosgratis.com.br/op000012.pdf

Paiva, V., Calazans, G., Venturi, G., \& Dias, R. (2008). Idade euso de preservativo na iniciação sexual deadolescentes brasileiros. Revista de Saúde Pública, 42(supl 1), 45-53. doi:10.1590/S0034-89102008000800007
Santos, S. M. P. S., Gonçalves, R. L., Azevedo, E. B., Pinheiro, A. K. D., Barbosa, C. A., \& Costa, K. N. F. (2014). A vivência da sexualidade por mulheres no climatério. Rev Enferm UFSM, 4(1), 113-122. doi:10.5902/217976928819

Saraiva, E. R. A. (2010). Violência contra idosos: aproximações e distanciamentos entre a fala do idoso $e$ o discurso da mídia impressa (Tese de Doutorado). Universidade Federal da Paraíba, João Pessoa, PB.

Silva, R. M. O. (2006). Sexualidade no idoso. In L. H. H. Hargreaves (Ed.), Geriatria (pp. 141-148). Brasília, DF: SEEP.

Trindade, Z. A., Santos, M. F. S., \& Almeida, A. M. O. (2011). Ancoragem: notas sobre consensos e dissensos. In A.M.O. Almeida, M. F. S. Santos, \&Z.A. Trindade (Eds.), Teoria das representações sociais 50 anos (pp. 101-121). Brasília, DF: Technopolitik.

Valença, C. N., Nascimento Filho, J. M., \& Germano, R. M. (2010). Mulher no climatério: reflexões sobre desejo sexual, beleza e feminilidade. Saúde e Sociedade, 19(2), 273-285. doi:10.1590/S0104-12902010000200005

\section{Kay Francis Leal Vieira}

Psicóloga. Mestre e Doutora em Psicologia Social pela Universidade Federal da Paraíba- UFPB. Docente do Centro Universitário de João Pessoa - UNIPÊ, João Pessoa-PB. Brasil.

E-mail: kayvieira@yahoo.com.br

Renata Pires Mendes da Nóbrega

Psicóloga. Graduação em Psicologia pelo Centro Universitário de João Pessoa-UNIPÊ, João Pessoa-PB. Brasil.

E-mail: renata_pmn@hotmail.com

Maria Valdênia Soares Arruda

Psicóloga. Graduação em Psicologia pelo Centro Universitário de João Pessoa - UNIPÊ, João Pessoa - PB. Brasil.

E-mail: valdenia.arruda@hotmail.com

Priscila Monique de Melo Veiga

Psicóloga. Graduação em Psicologia pelo Centro Universitário de João Pessoa - UNIPÊ, João Pessoa - PB. Brasil.

E-mail: prismonique25@hotmail.com 
Endereço para correspondência:

Rua: Comerciante José Miranda de Araújo, 130 apto

1001. Jardim Oceania. CEP: 58037-428.

João Pessoa - PB. Brasil.

Recebido: 18/08/2013

Reformulado: 23/07/2015

Aprovado:31/03/2016
Received: 08/18/2013

Reformulated: 07/23/2015

Approved: 03/31/2016

Recibido: 18/08/2013

Reformulado: $23 / 07 / 2015$

Aceptado: $31 / 03 / 2016$

Como citar: Vieira, K. F. L., Nóbrega, R. P. M., Arruda, M. V. S., \& Veiga, P. M. M. (2016). Representação social das relações sexuais: um estudo transgeracional entre mulheres. Psicologia: Ciência e Profissão, 36(2): 329-340. doi:10.1590/1982-3703001752013

How to cite: Vieira, K. F. L., Nóbrega, R. P. M., Arruda, M. V. S., \&Veiga, P. M. M. (2016). Social representation of sexual relations: a transgenerational study among women. Psicologia: Ciência e Profissão, 36(2): 329-340. doi:10.1590/1982-3703001752013

Cómo citar: Vieira, K. F. L., Nóbrega, R. P. M., Arruda, M. V. S., \& Veiga, P. M. M. (2016). Representación social de las relaciones sexuales: un estudio transgeneracional entre las mujeres. Psicologia: Ciência e Profissão, 36(2): $329-340$. doi:10.1590/1982-3703001752013 